\title{
APLICAÇÃO E USO DO SOFTWARE QUIMSIMULATOR NA DISCIPLINA DE QUÍMICA
}

\author{
APLICACIÓN Y USO DEL SOFTWARE QUIMSIMULATOR EN LA \\ ASIGNATURA DE QUÍMICA
}

\section{APPLICATION AND USE OF QUIMSIMULATOR SOFTWARE IN CHEMISTRY DISCIPLINE}

\author{
Simone Moraes STANGE ${ }^{1}$
}

RESUMO: Descreve as características e possibilidades de usos do aplicativo QuimSimulator, software idealizado como ferramenta de ensino-aprendizagem na disciplina de Química. Relaciona uma série de conceitos e argumentações que, num primeiro tempo, embasam os pressupostos pelos quais o projeto se orientou, num segundo tempo, validam os determinantes de público-alvo, atividades e perfiz de aplicação. Possibilita afirmar o alinhamento dos interesses de desenvolvimento de um processo pedagógico mais atual e dinâmico com as possibilidades de uso deste tipo de ferramenta.

PAlaVRAS-CHAVE: Ensino de química. Artefatos de comunicação. Processo pedagógico. Cultura digital.

RESUMEN: Describe las características y posibilidades de uso de la aplicación del software QuimSimulator, ideado como herramienta de enseñanza-aprendizaje en la asignatura de Química. Se relaciona una serie de conceptos y argumentaciones que, en un primer tiempo, basan los presupuestos por los cuales el proyecto se orientó, en un segundo tiempo, validan los determinantes de público objetivo, actividades y perfil de aplicación. Posibilita afirmar el alineamiento de los intereses de desarrollo de un proceso pedagógico más actual y dinámico con las posibilidades de uso de este tipo de herramienta.

PALABRAS-CLAVE: Enseñanza de química. Artefactos de comunicación. Proceso pedagógico. Cultura digital.

ABSTRACT: Describes the characteristics and possibilities of uses of the application QuimSimulator, software idealized as teaching-learning tool in the discipline of Chemistry. It relates a series of concepts and arguments that, in the first instance, support the assumptions by which the project was oriented; in the second phase, validate the determinants of the target audience, activities and application profile. It makes it possible to affirm the alignment of the interests of development of a more

${ }^{1}$ Universidade Federal de São Carlos (Ufscar), São Carlos - SP - Brasil. Doutoranda em Ciência, Tecnologia e Sociedade. Professora Mestra na Secretaria do Estado da Educação de Santa Catarina. Email: simonestangue@gmail.com.

RPGE - Revista on line de Política e Gestão Educacional, Araraquara, v.21, n.esp.3, p. 1691-1702, dez., 2017. 
current and dynamic pedagogical process with the possibilities of using this type of tool.

KEYWORDS: Chemistry teaching. Communication artifacts. Pedagogical process. Digital culture.

\section{Introdução}

Esta pesquisa se define como de caráter bibliográfico-exploratório e se orientou pela ordem de temas relacionados à cultura digital contemporânea e sua relação com o processo de comunicação, numa ótica educacional, se propondo, para tanto, como projeto de criação de um aplicativo, um software denominado QuimSimulator, destinado a desempenhar funções de jogo digital em instalações para smartphone e tablet, tendo como eixo temático os fundamentos, aplicações e história dos átomos e dos elementos químicos, tendo-se por: suporte didático de referência, a tabela periódica, e, público alvo, alunos da rede pública de ensino.

O objetivo principal foi o de discutir situações em que se demonstre estímulo ao processo de ensino/aprendizagem por meio da integração entre conteúdo didático e tecnologias de comunicação atuais (pelo uso dos artefatos mencionados anteriormente). Essa proposição se deu pelo interesse de convergência entre teoria e prática didática, pela abordagem do campo da Ciência, Tecnologia e Sociedade (CTS), combinando aspectos da comunicação cotidiana como complementos relevantes à formação do cidadão-aluno.

Sendo assim, considerando-se o público alvo e as atividades empreendedoras peculiares do projeto, considera-se que o software seja potencialmente promissor em sua proposta de alinhamento de recursos tecnológicos da ordem comunicacional na ordem pedagógica, pelo menos enquanto modelo de gerenciamento/disponibilização de conteúdos didático-pedagógicos. A Figura 1 apresenta uma ilustração de uso do software em um smartphone.

Figura : Telas de interface do software em um aparelho smartphone

Fonte: Brykcznski (2016)

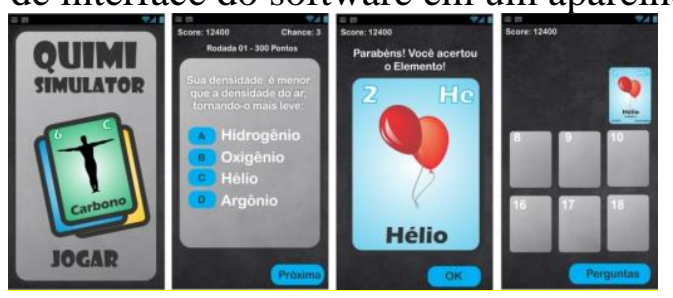

RPGE - Revista on line de Política e Gestão Educacional, Araraquara, v.21, n.esp.3, p. 1691-1702, dez., 2017. 
É possível perceber, tendo-se por referência os jogos digitais educacionais, que estes se caracterizam pela ação de estimular reações centradas no desafio dos participantes, sobretudo, no entorno do processo pedagógico, compondo-se de mecanismos que oportunizam o desenvolvimento físico e mental dos atores envolvidos no processo, possibilitando, portanto, o cumprimento de objetivos fundamentalmente lúdicos, mas, também educativos, por meio de processos inovativos e, satisfatoriamente, prazerosos, sejam de forma individual ou coletiva.

O mercado de software educacional se encontra em total expansão, carecendo, entretanto, de mais aplicativos voltados para educação, especialmente no ensino de química, aplicativos que tenham utilidade para o ensino e aprendizagem por meio de artefatos presentes no cotidiano dos alunos. Prisma pelo qual se advoga o uso de uma abordagem CTS, e seus enfoques interdisciplinares. Nos estudos de Meira (2014, p.1, grifo do autor), encontra-se um questionamento sobre "o lugar" da educação no uso de jogos educativos, observando que: “[...] educação é a décima sexta categoria em download [instalação] de jogos nos dispositivos android.”.

Em razão dessa situação, considera-se pertinente ratificar nosso interesse em defender a produção e uso de aplicativos que venham preencher essa lacuna. Desta forma, o instrumento didático ora descrito pretende contribuir para promoção/dinamização de uma forma de aprendizagem mais dinâmica, interativa e desafiadora.

De modo específico, o mercado de jogos digitais em nível nacional, está caracterizado pelo constante crescimento dos aparelhos celulares, sendo a partir da introdução do smartphone no mercado dos eletroeletrônicos, que surgiram novas possibilidades para utilização dos jogos digitais. Em um mapeamento realizado pela Universidade de São Paulo, em 2014, sobre a indústria de jogos digitais, descreve-se a seguinte realidade:

Em 2001, 31\% dos domicílios possuíam celular e 51\% telefone fixo. Este quadro se inverteu em 2004 e em 2009 78,5\% dos domicílios brasileiros possuíam celulares e $43,1 \%$, telefone fixo. [...], o celular passou a ser a preferência nas residências que tem apenas um telefone. Outra mudança, mais recente, é o crescimento da participação dos smart phones no mercado nacional. Enquanto nos seis primeiros meses de 2012 foram vendidos 6,8 milhões de smart phones e 20,5 milhões de feature phones, no terceiro trimestre de 2013 foram vendidos 10,4 milhões dos primeiros e 7,5 milhões dos segundos, isto é, a venda de smart phones superou a de feature phones, confirmando

RPGE - Revista on line de Política e Gestão Educacional, Araraquara, v.21, n.esp.3, p. 1691-1702, dez., 2017. 
a tendência verificada no segundo quadrimestre. (UNIVERSIDADE DE SÃO PAULO, 2014, p. 12).

Embora, esses dados retratem o potencial do mercado brasileiro, tendo-se em conta a demanda versus perspectivas de crescimento, também, é importante sinalizar que o aplicativo QuimSimulator, procurou se guiar por critérios didáticos e pedagógicos que, associados aos conceitos da química, buscam, prioritariamente, fortalecer o processo educacional como um todo, visando construir novas possibilidades de posicionamentos no sistema educacional formal.

A expressão das ideias registradas nesse trabalho procurou contextualizar seu respeito pela inclusão social, pela divulgação da cultura nacional, a melhoria da qualidade da escola pública, a interação entre empresas criativas, o fortalecimento das políticas públicas, enquanto molas propulsoras da economia e tecnologia, que alicerçam o panorama educacional brasileiro.

\title{
Fundamentação teórica
}

A Química apresenta, enquanto disciplina escolar, registros nos currículos brasileiros desde as primeiras décadas do século $\mathrm{XX}$, sendo instituída como um componente curricular no decurso da Reforma Francisco Campos, em 1931 (DALLABRIDA, 2009), pela qual se sinalizava a necessidade de se pensar em um ensino realizado em consonância com as situações cotidianas do aluno. Segundo os parâmetros curriculares nacionais:

\begin{abstract}
A Química pode ser um instrumento da formação humana que amplia os horizontes culturais e a autonomia no exercício da cidadania, se o conhecimento químico for promovido como um dos meios de interpretar o mundo e intervir na realidade, se for apresentado como ciência, com seus conceitos, métodos e linguagens próprios, e como construção histórica, relacionada ao desenvolvimento tecnológico e aos muitos aspectos da vida em sociedade (BRASIL, 2002, p. 87).
\end{abstract}

Assim, considera-se que agregar à prática educativa, novas metodologias, novas tecnologias, com abordagens fundamentadas em aportes científicos justificados, como os do campo da Ciência, Tecnologia e Sociedade (CTS), se qualificam como estratégias potencialmente promissoras, favorecedoras do desenvolvimento de novas relações com o saber, buscando-se a equalização de uma aprendizagem dialógica, no entorno da

RPGE - Revista on line de Política e Gestão Educacional, Araraquara, v.21, n.esp.3, p. 1691-1702, dez., 2017. 
Teoria da Aprendizagem de Ausubel (1982), a qual propõe que os conhecimentos prévios dos alunos sejam valorizados para que estes possam construir estruturas mentais que permitam descobrir e redescobrir outros conhecimentos, caracterizando, assim, uma aprendizagem prazerosa e eficaz, sobretudo pela contemplação de atividades que estimulem interações dinâmicas com objetos variados.

No contexto de nossa proposição, defende-se que os alunos precisam, seja qual for a categoria social que este pertença, estar em interação constante com o processo de construção de enunciados pedagógicos, sobretudo, estimulados à utilizarem os recursos tecnológicos como instrumentos de formação, abordando-os com o propósito de os transformarem para além dos aspectos lúdicos, espaços pedagógicos atrativos, articulados e inovadores do processo de ensino-aprendizagem. Caráter dinamizado por meio de uma cultura de ampliação do conhecimento por meio do mergulho no eixo de uma interdisciplinaridade inerente ao mundo.

Segundo Silva, Grochocki e Merkle (2011, p. 188):

É necessário garantir que iniciativas educacionais sedimentem-se como patrimônio das escolas, transformando a tecnologia em um bem apropriável pela comunidade, pelos educadores e principalmente pelos atuais e futuros educandos.

Nas concepções ora identificadas, ainda cabe destacar a exigência primordial de que os pais, ou responsáveis pelos educandos, atuem de maneira presente, disponibilizando-se para inserção cúmplice no acesso e uso do aplicativo aqui descrito, considerando-se a importância do envolvimento familiar na dinâmica educacional cidadã, enquanto partícipes para a evolução da educação dos filhos como cidadão alfabetizado (e alfabetizante) cientificamente.

As raízes estruturais do processo educacional, enquanto organização institucional, elucida a importância da concepção de um sujeito apto, e disponível, para deliberar estratégias de solução mediante situações-problema decorrentes do embate cotidiano, configurado pela grande diversidade de distintos graus de complexidade no mundo contemporâneo, ratificando-se o século XXI como era destinada ao desenvolvimento dos princípios de uma Sociedade do Conhecimento, que preconiza o movimento transformador estabelecido por uma profunda revolução nas políticas educacionais e na prática docente, que tomam o saber como fonte inesgotável e a ciência como terreno que exige aprimoramentos diários. 
Pela visão (não exclusiva) do campo CTS, a cada amanhecer novas descobertas são anunciadas e novos saberes são incorporados à sociedade global e local, configurando um painel de atores voltados ao empreendedorismo. A instituição escolar, nessa situação, é tida como centro de aprendizado, atentamente orientado, acompanhando inovações, implementando-as, almejando abarcar mercados mais promissores, interagindo com a comunidade, contribuindo com o avanço científico e tecnológico, formando cidadãos mais críticos, conscientes e pró-ativos.

\section{Perfil de uso e peculiaridades do software quimsimulator}

Considerando-se que a Química, para a maioria dos discentes, é uma disciplina vista como de difícil entendimento, e baixo rendimento na aprendizagem, o aplicativo QuimSimulator pretende contribuir para a melhoria da qualidade do seu ensino, tendo o docente como um referencial facilitador de um enfoque propício a estimular uma cadeia de processos cognitivos, suprimindo a lacuna de aplicativos específicos para o ensino de Química, numa vertente mais inovadora - uma vez que, em pesquisa prévia sobre o tema, se identificou a presença de aplicativos com tabelas periódicas de cunho mais tradicional.

O QuimSimulator se compõe, na versão aqui descrita, de perguntas sobre ocorrências, aplicações e/ou históricos sobre os átomos de elementos químicos. Se o aluno conseguir responder a pergunta chave de forma correta, ele ganha a carta correspondente ao elemento químico em questão (Figura 2). A partir dessa dinâmica, ele poderá acumular um número restrito de cartas, quantidade limitada pela meta de se completar a tabela atômica virtual. Caso o aluno consiga responder com adequação uma primeira rodada de perguntas, receberá uma maior pontuação, caso não consiga, obterá quatro outras oportunidades, recebendo, no entanto, pontuações menores. Cabe observar, ainda, que o processo possibilita compartilhamento (e troca) das cartas acumuladas com outros discentes relacionados à rede de jogadores do aplicativo.

Figura 2: Carta Carbono e Carta Ferro.

Fonte: Brykcznski (2016)

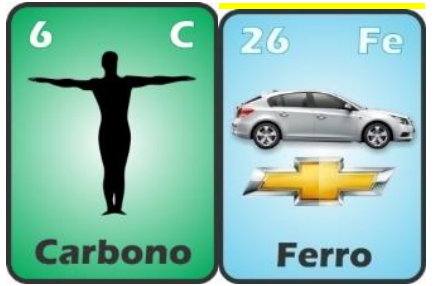

RPGE - Revista on line de Política e Gestão Educacional, Araraquara, v.21, n.esp.3, p. 1691-1702, dez., 2017. 
Considera-se pertinente salientar que o valor estabelecido para as cartas se valerá de um juízo simbólico relacionado com o grau de dificuldade em adquiri-las, assim como, supostamente, as cartas compartilhadas trarão benefícios de pontuação para o compartilhador, colocando-o em melhores posições de pontuação pela manutenção da ideia de time/equipe/dupla. Outros segmentos de benefício são determinados pela compra de outras cartas ainda não localizadas, mas necessárias para a contemplação do objetivo central: obtenção do maior número/pontuação pelas cartas do jogo.

No sentido de contribuir para a ampliação de conhecimento científico, social, cultural e tecnológico, por meio do elemento lúdico, e mediante o fato do jogo digital estar vinculado, também, ao desenvolvimento de raciocínio lógico, considera-se positivo e estimulante que cada segmento de alunos seja estabelecido por meio de diferentes versões do produto, conferindo a cada grupo um referencial identitário específico, visualizado por estilos de configuração passíveis de manipulação pelos envolvidos.

Na busca de caracterizar a faixa de público alvo para aplicação desse projeto, pesquisando-se no entorno do telemóvel com funcionalidade avançada, identificou-se, segundo dados da Agência Nacional de Telecomunicações (ANATEL), mais de 265 milhões de linhas telefônicas ativas no Brasil. No que concerne aos grupos humanos interessados no uso de aplicativos em sala de aula, se observa que, além da categoria Alunos, a categoria Docentes também deva ser considerada como elemento dinâmico, tanto da prescrição de uso quanto da funcionalidade pedagógica deste tipo de ferramenta.

O fatores e benefícios oferecidos pelo aplicativo QuimSimulator foram concebidos na intenção de abrangerem diversas atividades circunscritas no âmbito de formação do Ensino Médio, tais como:

Exame Nacional do Ensino Médio (ENEM): tendo por objetivo avaliar o desempenho do educando ao fim da escolaridade básica, compõe-se de um público de educandos em fase de conclusão, e, portanto, é considerado como critério de seleção para os educandos que pretendem concorrer a uma bolsa no Programa Universidade para Todos (ProUni). Atualmente, aproximadamente 500 universidades utilizam seus resultados para determinarem o ingresso no ensino superior, seja por complementação ou substituição do vestibular;

Programa Nacional Olimpíadas de Química: tendo por objetivo a promoção de jogos competitivos entre educandos do ensino médio e tecnológico de todo o país em 
modalidades denominadas: Junior $\left(8^{\circ}\right.$ e $9^{\circ}$ anos do ensino fundamental), podendo participar estudantes de escolas públicas ou privadas; Modalidade $\mathrm{A}\left(1^{\circ}\right.$ e $2^{\circ}$ anos do ensino médio), os medalhados de uma primeira etapa prosseguem em etapas posteriores, representado o Brasil em âmbito internacional; e, Modalidade B ( $3^{\circ}$ ano do ensino médio), pela qual são inscritos os estudantes que participaram da olimpíada estadual de química

Feiras de Ciências, Tecnologia, Educação e Cultura: que têm por objetivo disseminar a cultura da investigação, as ferramentas e os materiais em nível técnico, científico e cultural, que por sua vez, perfazem o potencial de aplicação no desenvolvimento e no apoio ao processo de ensino e de aprendizagem.

Prêmio Professores do Brasil: uma iniciativa do Ministério da Educação (MEC) em parceria com as secretarias de educação e outras instituições que tem por objetivo reconhecer o mérito dos educadores das redes públicas de ensino, por meio da contribuição dada para a melhoria da qualidade da educação básica.

Outro elemento digno de nota é que o recurso, em seu caráter interativo, também possibilitaria o enriquecimento - com o devido agenciamento/planejamento/execução das ações de alimentação compartilhada - de conteúdos/conhecimentos temáticos sóciocientíficos contextualizados pelo momento contemporâneo, sem, no entanto, perderem sua qualidade teórica disciplinar - o que não infere deslocamento da proposta interdisciplinar anteriormente apontada (uma vez que a exigência de conhecimento disciplinar é uma característica essencial para a dinâmica inter, multi ou transdisciplinar). Nas palavras de Morin (2001, p. 18), “[...] é preciso substituir o pensamento que isola e separa pelo pensamento que distingue e une.”.

Situando a presente discussão sobre o aspecto de conteúdo, de modo geral, o ensino tradicional de Química se apresenta fundamentado em aspectos formais, tendo um currículo delineado por uma tendência que se desvincula das origens científicas, bem como do meio social e tecnológico. Lopes (1995) afirma que esse tipo de currículo se reveste de um número excessivo de conceitos, cuja inter-relação é dificilmente percebida pelos educandos. Tal circunstância normatiza uma enfadonha memorização sistemática, não conduzindo ao conceito central da Teoria de Aprendizagem, anteriormente citada.

No que concerne ao eixo de capacitação profissional, Castilho, Silveira e Machado (1999) sustentam que a formação profissional do educando se edifica ao longo da vida, exigindo-se para tanto, uma reavaliação constante da relevância, do sentido e 
das contribuições da ciência Química no entorno do pensamento dialético e crítico, versando, necessariamente, numa atualização cotidiana do estado da arte do trabalhador, esteio de seu ambiente/estado profissional. Por esta razão, Maldaner e Piedade (1995) abordam o efeito positivo na aquisição de uma nova postura dos docentes - e, por conseguinte, das instituições, acerca das necessidades do ensino tecnológico, focados, aqui, no ensino de Química.

$\mathrm{Na}$ perspectiva de contribuições da articulação entre conhecimentos e níveis interativos de formação, Chassot (1993) assegura que o conhecimento químico oportuniza ao sujeito abstrair múltiplas leituras do mundo em que vive, à luz da interação entre a representação e a linguagem utilizada para expressá-la, o que significa dizer que, a relevância da socialização dos educandos é uma realidade da qual não se pode fugir - pelo menos, no que se refere ao cenário que se descortina no momento contemporâneo: um ensino pautado na ciência, mas que traz em si, o princípio do diálogo para os contextos além dos da sala de aula, enfatizando-se que a inclusão das Tecnologias da Informação e da Comunicação (TICs) tem se mostrado, potencialmente edificantes para a construção do conhecimento como um todo.

Em contraponto a essa percepção, Bernardelli (2004, p. 2) comenta acerca dos alunos:

\begin{abstract}
Muitos adquirem certa resistência ao aprendizado da química devido à falta de contextualidade, não conseguindo relacionar os conteúdos com o dia-a-dia, bem como a excessiva memorização, e ainda alguns professores insistem em métodos nos quais os alunos precisam decorar fórmulas, nomes e tabelas [...] devemos criar condições favoráveis e agradáveis para o ensino-aprendizagem da disciplina, aproveitando, no primeiro momento, a vivência dos alunos, os fatos do dia-a-dia, a tradição cultural e a mídia, buscando reconstruir os conhecimentos químicos para que o aluno possa refazer a leitura do seu mundo.
\end{abstract}

A partir dessa constatação, confirma-se, então, a urgência em propiciar ao educando atividades pedagógicas em que este possa organizar seu pensamento, de forma a elaborar conhecimento com coesão, e que, principalmente, em meio a tudo isso, se sinta satisfeito, e realizado, pelo ato de aprender. Defende-se que esse sentimento se dê em tal grau que as TICs passem a incorporar um rigor pedagógico menos apavorante, possibilitando melhor performance no conhecimento coetâneo, suprindo lacunas na longa trajetória que o ensino e o aprendizado vem trilhando ao longo dos séculos. 
Para Kenski (2000), os espaços virtuais das instituições escolares se estruturam essencialmente como linguagens, oportunizando o compartilhar de fluxos e mensagens na multiplicação dos saberes. Nesse caso, a autorrealização do aluno será expressa pelo prazer em aprender, gerando um melhor rendimento escolar pelo sentimento de pertencimento. Dessa forma, o aplicativo QuimSimulator, enquanto produto tecnológico, pretende estimular uma interação e compartilhamento maior entre docentes, discentes e seus pares, promovendo, neste encadeamento sociocultural, um jogo representativo da atividade pedagógica, libertário de convenções deterministas e impositivas.

Freire (2000, p. 102) considera que:

O exercício de pensar o tempo todo, de pensar a técnica, de pensar o conhecimento enquanto se conhece, de pensar o quê das coisas, o para quê, o como, o em favor de quê, de quem, o contra quê, o contra quem são exigências fundamentais de uma educação democrática à altura dos desafios do nosso tempo.

Nesse contexto, considera-se que as mutações contemporâneas do ensinoaprendizagem estão balizadas em três instâncias, ocorridas em sociedades orientadas por diretrizes impostas por um caráter: informacional; global; e, científica e tecnicamente civilizatório. Com base nestes fenômenos complexos é que a sociedade da informação (Information Society), a Sociedade do Conhecimento (Knowiedge Society) e a Sociedade Aprendiz (Learning Society) dão ênfase à abordagem analítica, em dimensões sociais, políticas, econômicas, educacionais, tecnológicas e culturais, contribuindo para o avanço da sociologia do conhecimento e da sociologia da ciência.

O aplicativo é considerado de fácil entendimento e uso, sendo exigido apenas o equipamento tablet ou smartphone para sua portabilidade, seguindo a prescrição de Crawford (1982) sobre a contemplação de níveis de "representação, interação, conflito e segurança" eficientes, tidos como quatro elementos fundamentais para que todo e qualquer jogo se mantenha interessante, desafiador, promovendo estímulo, satisfação e bem estar nos liames que formam os aspectos lúdicos, culturais, educacionais e sociais.

Nesse sentido Juul (2005), estima seis requisitos básicos para que todo jogo seja, realmente, validado como ferramenta de desenvolvimento do interesse, considerando que o jogo: se configure como um sistema formal baseado em regras, com resultados variáveis e quantificáveis, e que, a cada resultado obtido seja possível associar valores distintos pelos quais os jogadores se sintam estimulados a cumprir metas de esforços 
para atingirem o resultado proposto, sentindo-se emotivamente ligados a este, gerando consequências resultantes de opções e negociações dinâmicas.

\section{Considerações finais}

Com aspecto relevante da conclusão sobre a proposta de utilização do software QuimSimulator é possível afirmar que existe uma série de condições potencialmente promissoras, condições essas, expressas pelos teóricos analisados durante a identificação de características do tipo de incursão pela qual nossa proposição de orientou: uso de artefatos tecnológicos atrativos (jogos) para desenvolvimento de aspectos pedagógicos no entorno de atividades de ensino aprendizagem no contexto cultural e social contemporâneos.

Tanto características atribuídas ao perfil quanto às peculiaridades do aplicativo sugerido, foram abordados do ponto de vista teórico (com base nas preleções de autores e discursos proeminentes do campo da Educação), reconhecendo-se, portanto, a necessidade de uma abordagem mais empirista, orientada pela observação do uso, em campo, do software, registrando ocorrências práticas de sua aplicação.

Dessa maneira, a contribuição percebida por nossa proposição se localiza na defesa de uma educação mais coadunada com a realidade contemporânea, passível de ser estudada e fortalecida pela aquisição de componentes pedagógicos não tradicionais que, com base em dinâmicas interativas e interdisciplinares, possam prover o ambiente de sala de aula tanto do enriquecimento teórico quanto do prazer do aprendizado lúdico.

\section{REFERÊNCIAS}

AUSUBEL, D. P. A aprendizagem significativa: a teoría de David Ausubel. São Paulo: Moraes, 1982.

BERNARDELLI, M. S. Encantar para ensinar - um procedimento alternativo para o ensino de química. In: Convenção Brasil Latino América, Congresso Brasileiro e Encontro Paranaense de Psicoterapias Corporais. 1., 4., 9., 2004, Foz do Iguaçu. Anais... Foz do Iguaçu: Centro Reichiano, 2004.

BRASIL. Ministério da Educação (MEC). Secretaria de Educação Média e Tecnológica (Semtec). PCN + Ensino médio: orientações educacionais complementares aos Parâmetros Curriculares Nacionais: ciências da natureza, matemática e suas tecnologias. Brasília: MEC; Semtec, 2002.

CASTILHO, D. L.; SILVEIRA, K. P.; MACHADO, A. H. As aulas de química como espaço de investigação e reflexão. Quím. Nov. Esc., v. 9, p. 14-17, maio 1999. 
CHASSOT, A. Catalisando transformações na educação. Ijuí: Ed. Inijuí, 1993.

CRAWFORD, C. The art of digital game design. Vancouver: Washington State University, 1982.

DALLABRIDA, N. A reforma Francisco Campos e a modernização nacionalizada do ensino secundário. Educação, Porto Alegre, v. 32, n. 2, p. 185-191, maio/ago. 2009.

FREIRE, P. Pedagogia da indignação: cartas pedagógicas e outros escritos. São Paulo: Unesp, 2000.

JUUL, J. Half-Real: video games between real rules and fictional worlds. London: The MIT Press, 2005.

LOPES, A. R. C. Reações químicas: fenômeno, transformação e representação.Quím. Nov. Esc., n. 2, nov. 1995.

MALDANER, O. A.; PIEDADE, M. C. T. Repensando a química: a formação de equipes de professores/pesquisadores como forma eficaz de mudança da sala de aula de química. Quím. Nov. Esc., n. 1, p. 15-19, maio 1995.

MEIRA, S. Cadê os jogos educacionais móveis? Dia a dia, bit a bit, 2014. Disponível em: <http://boletim.de/silvio/sem-categoria/cad-os-jogos-educacionais-mveis/>. Acesso em: jun. 2016.

MORIN, E. A cabeça bem-feita: repensar a reforma, reformar o pensamento. Rio de Janeiro: Bertrand Brasil, 2001.

SILVA, R. B.; GROCHOCKI, L. R.; MERKLE, L. E. Implantação de robótica educacional em Guarapuava/PR. In: SILVEIRA, R. A.; FERREIRA FILHO, R. C. M. Ações institucionais de avaliação e disseminação de tecnologias educacionais. 1.ed. Porto Alegre JSM Comunicação, 2011.

UNIVERSIDADE DE SÃO PAULO. Mapeamento da indústria brasileira e global de jogos digitais. São Paulo: Universidade de São Paulo, 2014. Disponível em: <http://www.bndes.gov.br/SiteBNDES/bndes/bndes_pt/Galerias/Arquivos/conheciment o/seminario/seminario_mapeamento_industria_games042014_Relatorio_Final.pdf>. Acesso em: 19 out. 2016.

\section{Como referenciar este artigo}

STANGE, Simone Moraes. Aplicação e uso do software quimsimulator na disciplina de química. Revista on line de Política e Gestão Educacional, Araraquara, v.21, n.esp.3, p. 1691-1702, dez., 2017. ISSN: 1519-9029. 